\title{
Septin 9 methylated DNA is a sensitive and specific blood test for colorectal cancer
}

\author{
Jorja D Warren', Wei Xiong ${ }^{1}$, Ashley M Bunker ${ }^{2}$, Cecily P Vaughn² ${ }^{2}$ Larissa V Furtado ${ }^{3}$, William L Roberts ${ }^{3}$, \\ John C Fang ${ }^{4}$, Wade S Samowitz ${ }^{3}$ and Karen A Heichman ${ }^{1,3^{*}}$
}

\begin{abstract}
Background: About half of Americans 50 to 75 years old do not follow recommended colorectal cancer (CRC) screening guidelines, leaving 40 million individuals unscreened. A simple blood test would increase screening compliance, promoting early detection and better patient outcomes. The objective of this study is to demonstrate the performance of an improved sensitivity blood-based Septin 9 (SEPT9) methylated DNA test for colorectal cancer. Study variables include clinical stage, tumor location and histologic grade.

Methods: Plasma samples were collected from 50 untreated CRC patients at 3 institutions; 94 control samples were collected at 4 US institutions; samples were collected from 300 colonoscopy patients at 1 US clinic prior to endoscopy. SEPT9 methylated DNA concentration was tested in analytical specimens, plasma of known CRC cases, healthy control subjects, and plasma collected from colonoscopy patients.

Results: The improved SEPT9 methylated DNA test was more sensitive than previously described methods; the test had an overall sensitivity for CRC of $90 \%$ ( $95 \% \mathrm{Cl}, 77.4 \%$ to $96.3 \%$ ) and specificity of $88 \%$ (95\% Cl, $79.6 \%$ to $93.7 \%$ ), detecting CRC in patients of all stages. For early stage cancer (I and II) the test was 87\% (95\% Cl, 71.1\% to 95.1\%) sensitive. The test identified CRC from all regions, including proximal colon (for example, the cecum) and had a 12\% false-positive rate. In a small prospective study, the SEPT9 test detected 12\% of adenomas with a false-positive rate of $3 \%$.

Conclusions: A sensitive blood-based CRC screening test using the SEPT9 biomarker specifically detects a majority of CRCs of all stages and colorectal locations. The test could be offered to individuals of average risk for CRC who are unwilling or unable to undergo colonscopy.
\end{abstract}

\section{Background}

It has been postulated that a screening test for colorectal cancer (CRC) performed on blood that is collected in the physician's office would encourage more patients to undergo screening, and could significantly decrease CRC mortality. Increased screening would also likely result in cost savings to the healthcare system, since more CRCs would be detected at an earlier stage and newer, more expensive chemotherapies could be avoided [1]. In 2008, Lofton-Day et al. [2] described three blood-based molecular biomarkers for CRC that are shed from solid tumors into the bloodstream [3-5]. The same group further developed an assay to detect one of the candidates, Septin 9

\footnotetext{
* Correspondence: karen.heichman@aruplab.com

'New Technology Group, ARUP Laboratories, Inc., 500 Chipeta Way, Mail Code 209, Salt Lake City, UT 84108-1221, USA

Full list of author information is available at the end of the article
}

(SEPT9), which was differentially methylated in CRC tissues [6] and can be sensitively and specifically detected in blood plasma [7,8]. SEPT9 DNA methylation was analyzed in several case-control studies, involving more than 3,000 subjects, which demonstrated an overall CRC detection rate of 60 to 70\% [7-9]. In 2010, the PRESEPT prospective screening study of the SEPT9 biomarker was completed, and the results were presented at the 2010 Digestive Disease Week (DDW) conference [10]. Nearly 8,000 asymptomatic patients from 32 clinical sites in the United States and Germany undergoing routine screening colonoscopy participated in the study [10]. Blood was collected for each subject, and the results of the SEPT9 test were compared to colonoscopy with regard to CRC detection [10]. The SEPT9 test detected $67 \%$ of CRCs and had a false-positive rate of $11 \%$ [10], similar to results obtained in the previous case-control studies.

\section{Biomed Central}

(c) 2011 Warren et al; licensee BioMed Central Ltd. This is an Open Access article distributed under the terms of the Creative Commons Attribution License (http://creativecommons.org/licenses/by/2.0), which permits unrestricted use, distribution, and reproduction in any medium, provided the original work is properly cited. 
In this report, we describe an improved SEPT9 bloodbased CRC screening test with a significant increase in sensitivity. Employing recent improvements for duplexing, amplifying and detecting SEPT9 methylated DNA, we demonstrate that the new test has dramatically improved performance when compared to the PRESEPT study method. In a case-control study, the new SEPT9 test is demonstrated to specifically identify CRCs from blood plasma with sensitivity similar to colonoscopy, exceeding the rates published for stool-based tests and previously described SEPT9 blood tests. The ability of the test to detect cancers originating from all large intestine locations is presented.

\section{Methods}

\section{Human Plasma Samples}

The clinical performance of the SEPT9 methylated DNA assay was measured using blinded plasma specimens collected from CRC patients and colonoscopy-verified control subjects. Specimens were collected from 50 untreated CRC patients prior to surgery at one US and two Russian institutions between July 2008 and March 2009. The average age of the cancer patients was 62 (range: 42 to 85 ) years. Control specimens were collected from 94 CRC-free subjects at four institutions in the US within one year of having a negative colonoscopy; collections occurred between July 2008 and June 2010. Control subjects had an average age of 58 (range: 40 to 86 ) years. A separate set of controls involving 98 younger subjects between the ages of 18 to 49 was collected at ARUP Laboratories between January and April 2011. The average age in this group was 32.

For the small prospective study, blood specimens were collected from 306 patients undergoing colonoscopy at a single community clinic in the US from March to June 2011; 300 of the subjects were evaluable. The average age of the cohort was 56 (range: 22 to 84) years; 195 of these were 50 to 75 (average 59) years of age, were asymptomatic, and underwent a routine screening colonoscopy.

Written informed consent was obtained from all study participants, adhering to local ethics guidelines.

\section{Laboratory Methods}

Analytical performance of the blood-based SEPT9 assay

Analytical performance of the assay was determined using CpGenome wholly methylated human genomic DNA (Chemicon/Millipore, Billerica, Massachusetts) added to pooled normal human plasma (Innovative Research, Novi, Michigan). The limit of detection of SEPT9 methylated DNA at the specimen level was $6.25 \mathrm{pg} / \mathrm{ml}$ (at least one out of the three reactions had SEPT9 detected $100 \%$ of the time). The limit of detection at the PCR replicate level was $50 \mathrm{pg} / \mathrm{ml}$ (all three out of three reactions had SEPT9 detected $100 \%$ of the time). For the comparison study with the PRESEPT Epi proColon PCR method, concentrations ranging from 6.25 to $100 \mathrm{pg} / \mathrm{ml}$ of wholly methylated human genomic DNA were used. DNA was extracted from multiple aliquots of each concentration, treated with bisulfite, and purified. Resultant DNA samples from each concentration were pooled, so that the same DNA substrate was used in the PCR method comparisons.

\section{DNA Preparation and Bisulfite Conversion from Plasma Specimens}

For each subject, $10 \mathrm{ml}$ of blood was collected in an EDTA (ethylenediaminetetraacetic acid) vacutainer tube. Each tube was centrifuged for 12 minutes at $1350 \times \mathrm{g} \pm 150 \times \mathrm{g}$ at room temperature. Plasma was transferred without disturbing the buffy coat to a clean $15 \mathrm{ml}$ conical tube. The sample was centrifuged a second time for 12 minutes at $1350 \times \mathrm{g} \pm 150 \times \mathrm{g}$. Plasma was transferred without disturbing the pellet to a $4 \mathrm{ml}$ tube and stored at $-70^{\circ} \mathrm{C}$. Total genomic DNA was extracted from $4 \mathrm{ml}$ of plasma using a nucleic acid extraction kit from Chemagen (Chemagic NA Extraction kit catalog number 1045 distributed by PerkinElmer, Waltham, Massachusetts) following the product insert protocol. Sample DNA was treated with bisulfite conversion reagents prepared according to the protocol from deVos et al. [8]. All bisulfite reagents were purchased from Sigma-Aldrich (St. Louis, Missouri). After bisulfite conversion, samples were purified using a bisulfite purification kit from Chemagen (Chemagic Bisulfite Purification Kit number 1036) following the product insert protocol. DNA was eluted in $55 \mu \mathrm{L}$ of elution buffer. If not used immediately, eluted DNA was stored at $-20^{\circ} \mathrm{C}$ for up to one week.

\section{Real-Time PCR}

PCR amplification was performed in triplicate for each sample using a modified version of the protocol from deVos et al. [8]. Septin 9 (SEPT9) and beta-actin (ACTB) control reactions were performed in the same reaction. All primers and probes were synthesized by Integrated DNA Technologies (Coralville, Iowa). Qiagen (Germantown, Maryland) 2X QuantiTect Multiplex Kit No ROX was used. The total volume of the PCR was $25 \mu \mathrm{L}$ using $10 \mu \mathrm{L}$ DNA and $12.5 \mu \mathrm{L} 2 \mathrm{X}$ QuantiTect Kit. Sequences and final concentrations were as follows: SEPT9-FWD AAATAATCCCATCCAACTA $(1.5 \mu \mathrm{M})$, SEPT9-REV GATT-dSp-GTTGTTTATTAGTTATTATGT $(1.5 \mu \mathrm{M})$, SEPT9-Blocker GTTATTATGTTGGATTTTGTGGTTAATGTGTAG-SpC3 $(1.0 \mu \mathrm{M})$, SEPT9-Probe FAMTTAACCGCGAAATCCGAC-BHQ_1 (0.075 $\mu \mathrm{M})$, ACTB-FWD GTGATGGAGGAGGTTTAGTAAGTT $(0.2 \mu \mathrm{M}), A C T B-R E V$ CCAATAAAACCTACTCCTCC CTTAA $(0.2 \mu \mathrm{M})$, ACTB-probe TEX615-ACCACCACCCAACACACAATAACAAACACA-IAbRQSp $(0.075 \mu \mathrm{M})$. Real-time PCR was performed on the LC480 thermal cycler (Roche Applied Science, Indianapolis, Indiana) using the following cycling conditions: activation at $95^{\circ} \mathrm{C}$ 
for 30 minutes, 50 cycles of $95^{\circ} \mathrm{C}$ for 10 seconds, $56^{\circ} \mathrm{C}$ for 30 seconds, and final cooling to $40^{\circ} \mathrm{C}$ for 30 seconds. Heating rates were $4.4^{\circ} \mathrm{C} /$ second and cooling rates, $2.2^{\circ} \mathrm{C} / \mathrm{sec}-$ ond. Data were acquired at the end of each $56^{\circ} \mathrm{C}$ step. Samples were analyzed using the AbsQuant $/ 2^{\text {nd }}$ DerivativeMax function of the LC480 software. For the comparison study, the PCR method was performed as described in the Epi proColon Instructions For Use pamphlet (Epigenomics AG, Berlin, Germany). Analysis was done using the AbsQuant/Fit points function of the LC480 software following the Epi proColon real-time PCR protocol.

\section{PCR Data Analysis}

In order to maximize sensitivity, SEPT9 was called positive if at least one of the triplicate reactions had detectable SEPT9. For plasma specimens that contain very low levels of DNA, SEPT9 was 'detected' if the quantification cycle ('crossing point', $\mathrm{CP}$ ) was less than 45 cycles, the highest value reliably measured by the LC480 AbsQuant $/ 2^{\text {nd }}$ DerivativeMax analysis function. Plasma specimens were 'not detected' if the SEPT9 CP was not measurable or was $\geq$ 45.0 cycles and the $A C T B$ CP was $\geq 36.0$ cycles. If $A C T B$ was not detected, eluted DNA specimens were diluted 1:10 in water and re-run; for these studies, a CP of 39.0 cycles for $A C T B$ was the maximum value accepted in order to confirm a SEPT9 negative result.

\section{Statistical Analysis}

In the case control study, the sensitivity and specificity of the SEPT9 test for detecting CRC were calculated as follows:

\section{Sensitivity $=$ true positives/total cancers}

\section{Specificity $=$ false positives $/$ total controls}

95\% confidence intervals were calculated according to the efficient-score method (corrected for continuity) $[11,12]$. Negative and positive predictive values were calculated as follows:

Negative predictive value $(\mathrm{NPV})=$ true negatives/true negatives + false negatives

Positive predictive value $(\mathrm{PPV})=$ true positives/true positives + false positives

For these NPV and PPV calculations, the prevalence of CRC in the screening population was assumed to be 1 in 200 based on the work of Lieberman [13].

\section{Results}

\section{Analytical performance of the improved blood-based} SEPT9 test

The SEPT9 test presented in this publication was specifically developed to improve upon the method described by deVos [8] that was used in the PRESEPT screening study [10]. Each element of the deVos PCR detection protocol was specifically optimized, followed by the development of a robust duplex reaction whereby both SEPT9 and ACTB (internal control) were measured in the same reaction using different fluorescent tags, similar to the PRESEPT method. Both methods use essentially the same reagents and can be completed in roughly 24 hours, with approximately four hours of hands-on time. The critical alterations compared to the deVos and PRESEPT protocols are as follows: 1) SEPT9 PCR primer concentrations were increased; 2) $A C T B$ PCR primer concentrations were decreased; and 3) a different fluorescent label was used for the $A C T B$ probe. Figure 1 demonstrates the sensitivity of the improved protocol compared to the PRESEPT method using pooled human plasma spiked with various concentrations of methylated human DNA. The increased sensitivity of our method is exemplified by the 6.25 and 12.5 $\mathrm{pg} / \mathrm{ml}$ dilutions, whereby the improved protocol detected SEPT9 in an average of $40 \%$ of the replicates, while the PRESEPT method was only capable of detecting SEPT 9 an average of $5 \%$ of the time. Further, the detection of the SEPT9 signal occurred several cycles earlier in the improved PCR method compared to the PRESEPT protocol, demonstrating an increased sensitivity of at least ten-fold (Additional file 1, Supplementary Table 1).

\section{Clinical performance of the blood-based SEPT9 test}

In a case-control study using specimens blinded to the operator, the optimized SEPT9 test was able to identify 45 out of 50 cancers from the plasma of CRC patients, with an overall sensitivity of $90 \%$ (95\% confidence intervals $77.4 \%$ to $96.3 \%$ ). Three-quarters of the samples were contributed by patients with early stage disease (stages I and II), approximating the stage of disease typically detected during routine screening. The new SEPT9 test was able to detect 33 out of the 38 of these early cancers for a sensitivity of $87 \%$, and detected all late stage cancers (stages III and IV). Additional file 2, Supplementary Table 2 lists the subjects that participated in the study, including demographic and clinical information, together with SEPT9 and ACTB crossing points. SEPT9 was 'detected' if the crossing point of at least one out of three PCR replicates for each specimen had a value of less than 45 cycles. Figure 2 is a diagram illustrating the overall performance of the SEPT9 test, with each cancer stage shown individually. The SEPT9 test detected CRCs arising from all regions of the colon and rectum, including proximal tumors arising from the cecum and ascending colon (Additional file 2, Supplementary Table 2). Figure 3 illustrates the cancer detection frequency for each of the regions. The ten percent of tumors that were not detected by the assay were 


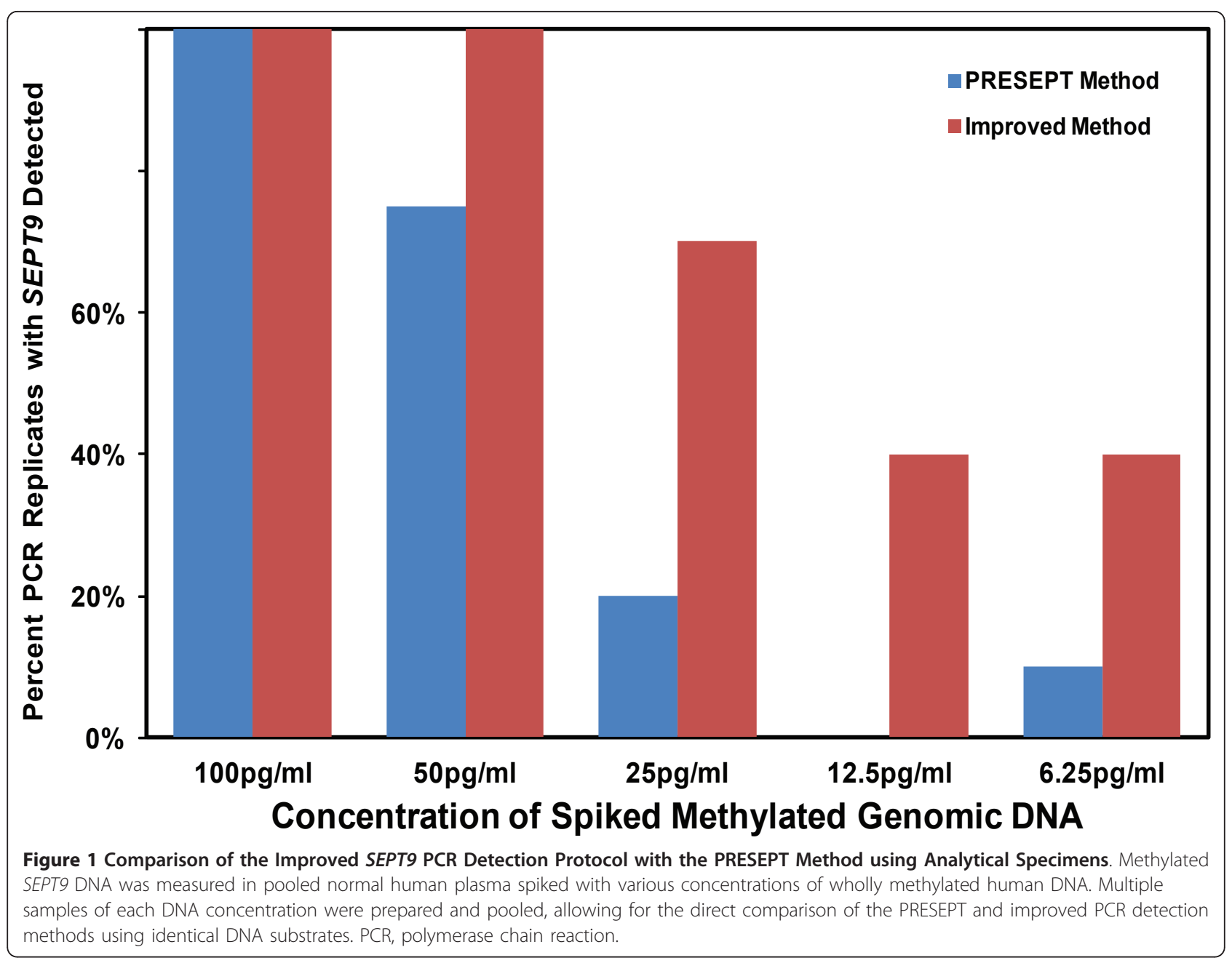

from a variety of regions of the lower GI tract. SEPT9 methylation was detected in 11 out of 94 of the control specimens collected from CRC-free colonoscopy-verified individuals age 40 and older (Additional file 3, Supplementary Table 3 ). The test had an overall specificity of $88 \%$, consistent with previous reports [2,7-9]. This falsepositive rate of $12 \%$ was relatively stable across different age cohorts from 50 to 75 , with only a slight increase to $12.5 \%$ in the age 69 to 75 subset. In a separate study, SEPT 9 methylation was tested in 98 healthy younger control subjects with no personal or family history of CRC between the ages of 18 to 49; in this group, SEPT9 methylated DNA was detected in $6 \%$ of the subjects (data not shown).

In order to gauge whether the improved SEPT9 test might be useful for detection of adenomas, blood was collected from 306 colonoscopy patients at a community clinic, none of whom were shown by colonoscopy to have colorectal cancer. In the entire set of 300 evaluable subjects (ages 24 to 83 years, average 56 ), only $12 \%$ of the 104 subjects with adenomas were detected using the
SEPT9 test (Table 1). The test was again shown to be specific, with an overall false-positive rate of $3 \%$. Similarly, in the true screening population, those asymptomatic individuals age 50 to 75 years (average 58 ), only $10 \%$ of individuals with adenomas were detected using the blood test. Although the adenoma detection rate was very low, more than half of the subjects in this study with detectable SEPT9 were found by colonoscopy to possess an adenoma or other polyp. The most common cause of a false-positive result was diverticulosis, which accounted for nearly half of the $3 \%$ false-positive rate.

\section{Discussion}

In several clinical studies, which together include over 10,000 subjects, SEPT9 has consistently demonstrated utility for detecting CRC in the blood, with previous publications citing a rate of $60 \%$ to $70 \%[2,7,8,10]$. In the PRESEPT prospective study of nearly 8,000 asymptomatic individuals undergoing routine CRC screening, the CRC detection rate was $67 \%$ with a specificity of $89 \%$, similar to results obtained in case-control studies 


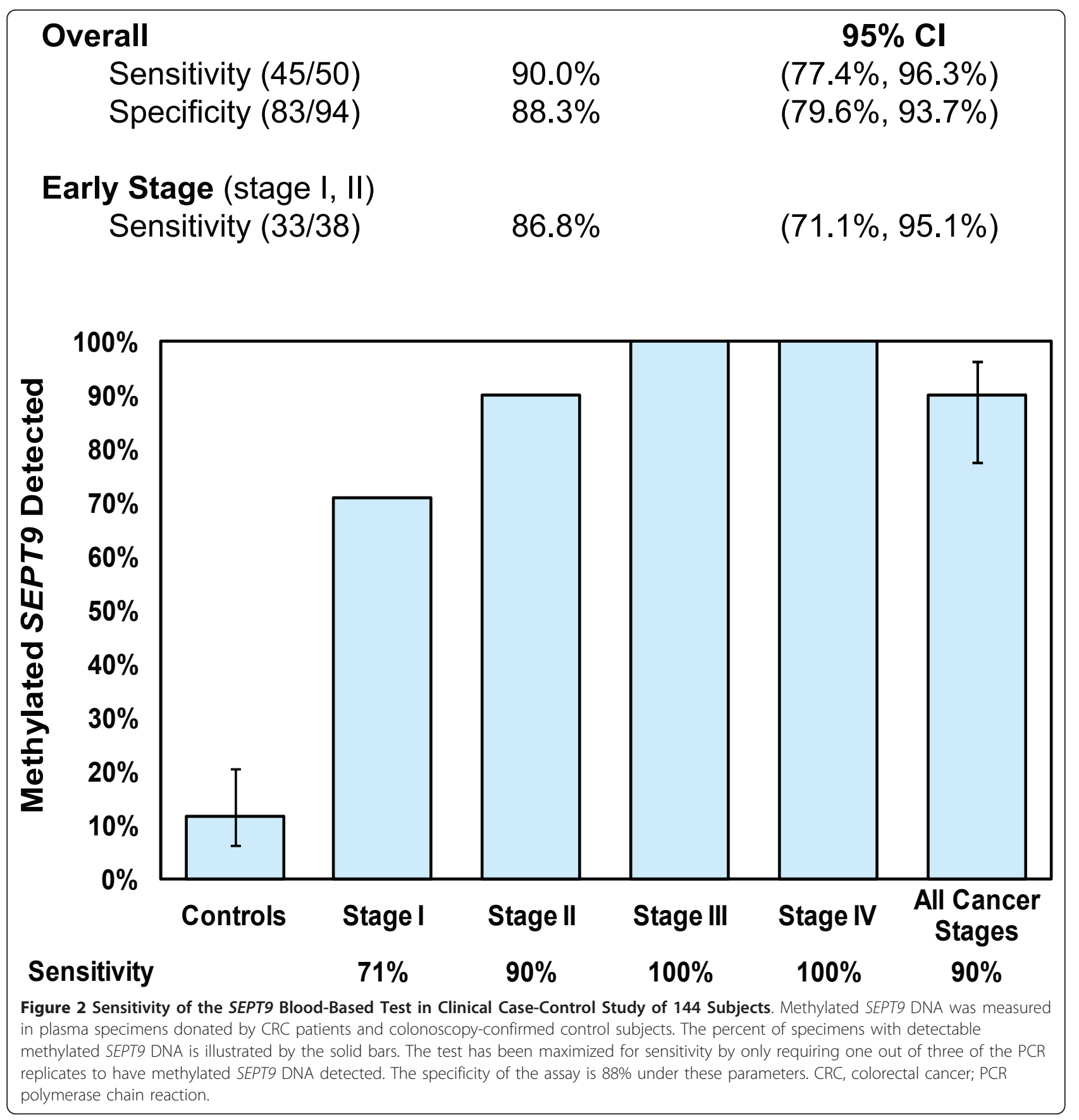

[10]. Our publication describes an improved SEPT9 blood test with enhanced sensitivity, proven by direct comparison with the PRESEPT method using identical analytical specimens. In a case-control study of 144 blinded specimens, the improved SEPT9 blood test detected cancers of all stages and colorectal locations, including $87 \%$ of early stage cases (stages I and II). The new test exhibited an overall CRC detection rate of $90 \%$ at $88 \%$ specificity, contrasting historical studies of SEPT9.
The SEPT9 test is performed as a duplexed PCR, with each reaction run in triplicate to maximize the amount of DNA specimen analyzed. As was originally described in previous SEPT9 methods, the improved test is currently configured to favor sensitivity over specificity, whereby SEPT9 must be detectable in only one out of three PCR replicates in order to call a positive test. Assuming a CRC prevalence of $0.5 \%$ in the screening population of individuals age 50 or older [13], and similar test performance in the screening setting as the case- 


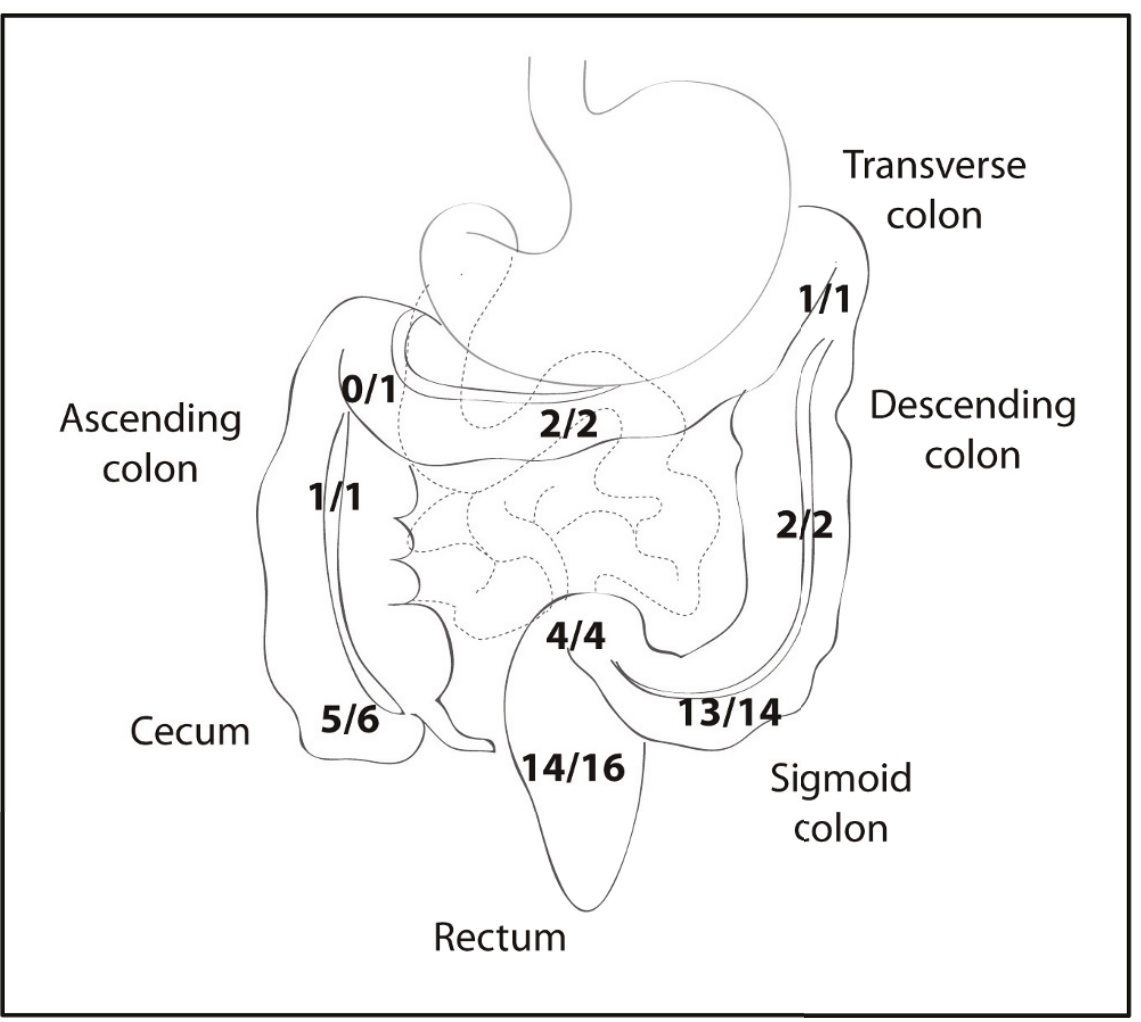

Figure 3 Location of Tumors Detected by SEPT9 Blood-Based Test. The diagram illustrates the locations of the primary tumors that were detected using the blood-based methylated SEPT9 DNA test. Note that CRCS were identified throughout the large intestine, including proximal regions such as the cecum. Three of the fifty blood specimens did not have tumor locations recorded, therefore these specimens are not represented by this figure. CRC, colorectal cancer.

control study presented here, the improved test would have a negative predictive value of $99.94 \%$ (Table 2). A more stringent variation of the test could be used to maximize specificity to $100 \%$, resulting in a positive predictive value of $100 \%$, however the sensitivity would be reduced to $70 \%$. While a $70 \%$ detection rate with $100 \%$ specificity might out-perform many of the other laboratory-based screening tests for detecting CRC, it is

Table 1 SEPT9 detection in specimens collected prospectively from colonoscopy patients

\begin{tabular}{lcccc}
\hline & \multicolumn{2}{c}{$\begin{array}{c}\text { All Evaluable } \\
\text { Subjects } \\
\text { (age 24-86 years) }\end{array}$} & $\begin{array}{c}\text { Asymptomatic Subjects } \\
\text { (age 50-75 years) }\end{array}$ \\
\hline Total subjects & Total & SEPT9 + & Total & SEPT9 + \\
Colorectal cancer & 300 & 21 & 195 & 0 \\
Other cancer (carcinoid tumor) & 0 & 0 & 0 & 0 \\
Adenoma & 1 & 0 & 78 & 8 \\
$\quad$ Adenoma $\leq 10$ mm & 104 & 12 & 69 & 7 \\
$\quad$ Adenoma $>10$ mm & 93 & 11 & 9 & 1 \\
Hyperplastic/other polyp & 11 & 1 & 27 & 1 \\
Diverticulosis & 38 & 1 & 27 & 3 \\
Hemorrhoids & 43 & 4 & 12 & 0 \\
Crohn's disease/colitis & 29 & 1 & 3 & 0 \\
Other colonic findings & 7 & 0 & 9 & 0 \\
Unsatisfactory prep/aborted & 21 & 0 & 9 & 3 \\
Normal & 11 & 0 & 34 & 0 \\
\hline
\end{tabular}


Table 2 Summary statistics for the SEPT9 test in colorectal cancer detection

\begin{tabular}{lccc}
\hline & Most Sensitive & Moderate Sensitivity, Moderate Specificity & Most Specific \\
\hline Positive PCR replicates & 1 out of 3 & 2 out of 3 & 3 out of 3 \\
Sensitivity & $90 \%$ & $76 \%$ & $70 \%$ \\
Specificity & $88 \%$ & $99 \%$ & $100 \%$ \\
Positive predictive value & $3.61 \%$ & $26.30 \%$ & $100 \%$ \\
Negative predictive value & $99.94 \%$ & $99.88 \%$ & $99.85 \%$ \\
\hline
\end{tabular}

our belief that a maximally sensitive method that would detect a majority of cancers in their early stages would provide a better screening option for the millions of otherwise unscreened individuals.

Although tissue studies showed that adenomas have elevated levels of methylated SEPT9 DNA comparable to CRCs (data not shown), the adenoma detection rate in the plasma was a modest $10 \%$ to $12 \%$, consistent with previous studies of the SEPT9 biomarker $[7,10]$ and similar to that reported for a standard guaiac fecal occult blood test (FOBT) [13]. Note that these early FOBT tests, which have been reported to detect lower percentages of colorectal cancers [13], were shown in several large prospective screening studies to provide a survival benefit to those who underwent screening when compared to those who did not [14-17]. There did not appear to be any specific types or size of adenomas that were more amenable to SEPT9 detection, although a more extensive study with larger numbers of specimens will be required. These results suggest that while the new method is very useful for detecting a majority of CRCs of all stages and locations from the plasma, a blood-based test for SEPT9 alone will not be sufficient to detect mucosal precancerous lesions.

Methylated SEPT9 may normally play a role in embryonic development in humans. In evaluating SEPT9 methylation in normal healthy young control subjects under the age of 50 years, four women demonstrated high concentrations of methylated SEPT9 DNA (Warren et al., unpublished data). These women were subsequently found to be pregnant. Additional studies with 20 pregnant women showed that $100 \%$ of these subjects had very high concentrations of methylated SEPT9 in their plasma. Like other well-known cancer biomarkers such as alpha-fetoprotein (AFP), carcinoembryonic antigen (CEA) and CA-125, SEPT9 is implicated in both embryogenesis and oncogenesis. Future studies are planned to determine whether the sensitive SEPT9 blood test might be useful for therapeutic monitoring and early detection of relapse, such as CEA and CA-125.

\section{Conclusions}

Although it is clear that CRC screening reduces mortality by detecting the disease in its earliest stages when it is most effectively treated [14-28], only one half of Americans age 50 and older currently undergo any kind of screening $[29,30]$. Patient compliance appears to be a major hurdle [31]. Even those individuals who otherwise adhere to screening recommendations for other cancers, such as those who routinely undergo mammography, do not faithfully follow colorectal screening guidelines [31]. Physician recommendation plays a significant role in whether individuals are screened [32], however patient preference appears to strongly determine what method, if any, is ultimately used [33]. Reasons for not complying with colonoscopy referral include the time-consuming nature of the procedure and concern about invasiveness [33]. Alternative methods for CRC screening such as fecal testing have declined in recent years [32]. In addition to the challenges of patient compliance with stool testing, such as the requirement for multiple samples and the handling of specimens, the performance of these tests is quite variable, with cancer detection rates ranging from $30 \%$ to $85 \%$ (13). Newer stool based tests such as the immunochemical FOBT (FIT), have demonstrated sensitivity for adenoma detection [1]. While the SEPT9 methylated DNA test may perform comparably to colonoscopy in detecting CRCs, it lacks the advantage of being potentially curative, and does not perform well for adenoma detection. Nonetheless, we believe that a bloodbased CRC test, whereby specimens are collected in the primary care setting every two or three years, will attract a significant fraction of those individuals who are otherwise non-compliant with recommended screening guidelines. Studies are underway to gain a better understanding as to whether a blood-based test will encourage individuals in the average risk screening population to undergo testing of this type.

\section{Additional material}

Additional file 1: Supplementary Table 1. Comparison of improved SEPT9 detection protocol with PRESEPT method using analytical specimens.

Additional file 2: Supplementary Table 2. Measurement of SEPT9 methylated DNA in plasma of colorectal cancer patients.

Additional file 3: Supplementary Table 3. Control Plasma Specimens.

\section{Abbreviations}

ACTB: beta-actin gene; AFP: alpha-fetoprotein; avg: average; C: centrigrade; CEA: carcinoembryonic antigen; CA-125: carbohydrate antigen 125; Cl: 
confidence interval; CP: crossing point; CRC: colorectal cancer; DDW: Digestive Disease Week; DNA: deoxyribonucleic acid; FIT: fecal immunochemical test; FOBT: fecal occult test; g: gravity; Gl: gastrointestinal: pg: picogram; $\mu$ l microliter; $\mu \mathrm{M}$ : micromolar; ml: milliter; NPV: negative predictive value; PCR: polymerase chain reaction; PPV: positive predictive value; SEPT9: septin 9 gene; US: United States.

\section{Acknowledgements}

We would like to thank all of the study participants for agreeing to participate in medical research. We also thank Dan Anderson for his insights into the clinical implementation of the test, Melinda Jones, Kyle Rasmussen and the staff of the University of Utah Redwood Health Center Endoscopy Clinic for help with study participant recruitment and specimen collection. Thank you to Maria Erali for her original artistic contribution to Figure 3 and Andy Wilson for statistical discussions. Finally, we are grateful to Noriko Kusukawa, Carl Wittwer and Bill Hokanson for critically reviewing this manuscript, and for many helpful discussions.

Financial support

This work was entirely funded by ARUP Laboratories, Inc., a not-for-profit, wholly-owned enterprise of the University of Utah

\section{Author details}

'New Technology Group, ARUP Laboratories, Inc., 500 Chipeta Way, Mail Code 209, Salt Lake City, UT 84108-1221, USA. ${ }^{2}$ ARUP Institute of Experimental Pathology, ARUP Laboratories, Inc., 500 Chipeta Way, Salt Lake City, UT 84108-1221, USA. ${ }^{3}$ University of Utah Department of Pathology, ARUP Laboratories, Inc., 500 Chipeta Way, Salt Lake City, UT 84108-1221, USA. ${ }^{4}$ Divison of Gastroenterology, University School of Utah Medicine, 30N 1900 E, Room 4R118, salt Lake City, UT 84132, USA.

\section{Authors' contributions}

JDW and WX developed the improved SEPT9 protocol. JDW performed all SEPT9 assays. CPV prepared tissue specimens for DNA extraction. LVF and WSS analyzed colon tissue specimens. AMB handled blood specimen collection, plasma sample preparation, and patient consent. KAH, WLR, WSS and JDW contributed to the clinical study design and experimental design. JCF contributed to the colonoscopy study design and specimen collection. KAH and JDW drafted the manuscript. All authors read, provided critical input, and approved the manuscript.

\section{Competing interests}

This study was funded exclusively by ARUP Laboratories, Inc., a non-profit national reference laboratory, which is a wholly owned enterprise of the University of Utah and its Department of Pathology. The study was designed and performed by ARUP employees and members of the University of Utah School of Medicine. None of the authors have any competing interests.

Received: 13 September 2011 Accepted: 14 December 2011 Published: 14 December 2011

\section{References}

1. Lansdorp-Vogelaar I, van Ballegooijen M, Zauber A, Habbema DF, Kuipers EJ: Effect of Rising Chemotherapy Costs on the Cost Savings of Colorectal Cancer Screening. J Natl Cancer Inst 2009, 101:1412-1422.

2. Lofton-Day C, Model F, deVos T, Tetzner R, Distler J, Schuster M, Song X, Lesche R, Liebenberg V, Ebert M, Molnar B, Grützmann R, Pilarsky C, Sledziewski A: DNA methylation biomarkers for blood-based colorectal cancer screening. Clin Chem 2008, 54:414-423.

3. Leon SA, Shapiro B, Sklaroff DM, Yaros MJ: Free DNA in the serum of cancer patients and the effect of therapy. Cancer Res 1977, 37:646-650

4. Shapiro B, Chakrabarty M, Cohn EM, Leon SA: Determination of circulating DNA levels in patients with benign or malignant gastrointestinal disease. Cancer 1983, 51:2116-2120.

5. Maebo A: Plasma DNA level as a tumor marker in primary lung cancer. Nihon Kyobu Shikkan Gakkai Zasshi 1990, 28:1085-1091.

6. Model F, Osborn N, Ahlquist D, Gruetzmann R, Molnar R, Sipos F, Galamb O, Pilarsky C, Saeger HD, Tulassay Z, Hale K, Mooney S, Lograsso J, Adorjan P, Lesche R, Dessauer A, Kleiber J, Porstmann B, Sledziewski A, Lofton-Day C: Identification and validation of colorectal neoplasia-specific methylation markers for accurate classification of disease. Mol Cancer Res 2007, 5:153-163.
7. Grützmann R, Molnar B, Pilarsky C, Habermann JK, Schlag PM, Saeger HD, Miehlke S, Stolz T, Model F, Roblick UJ, Bruch HP, Koch R, Liebenberg V, Devos T, Song X, Day RH, Sledziewski AZ, Lofton-Day C: Sensitive detection of colorectal cancer in peripheral blood by septin 9 DNA methylation assay. PLoS One 2008, 3:e3759.

8. deVos T, Tetzner R, Model F, Weiss G, Schuster M, Distler J, Steiger KV, Grützmann R, Pilarsky C, Habermann JK, Fleshner PR, Oubre BM, Day R, Sledziewski AZ, Lofton-Day C: Circulating methylated SEPT9 DNA in plasma is a biomarker for colorectal cancer. Clin Chem 2009, 55:1337-1346.

9. Tänzer M, Baluff B, Distler J, Hale K, Leodolter A, Röcken T, Molnar B, Schmid R, Lofton-Day C, Schuster T, Ebert MP: Performance of Epigenetic Markers SEPT9 and ALX4 in Plasma for Detection of Colorectal Precancerous Lesions. PLoS One 2010, 5:e9061.

10. Church TR, Wandell M, Lofton-Day C, Mongin SJ, Blumenstein BA, Allen Jl, Roesch T, Osborn N, Snover D, Day R, Ransohoff DF: Prospective clinical validation of an assay for methylated SEPT9 DNA in human plasma as a colorectal cancer screening tool in average risk men and women 50 years and older. Digestive Disease Week 2010, 1-5, LB-711d.

11. Newcombe RG: Two-Sided Confidence Intervals for the Single Proportion: Comparison of Seven Methods. Stat Med 1998, 17:857-872

12. Wilson EB: Probable Inference, the Law of Succession, and Statistical Inference. J Am Stat Assoc 1927, 22:209-212.

13. Lieberman DA: Clinical practice: Screening for colorectal cancer. N Engl J Med 2009, 361:1179-1187.

14. Hardcastle JD, Chamberlain JO, Robinson MH, Moss MH, Amar SS, Balfour TW, James PD, Mangham CM: Randomised controlled trial of faecal-occult-blood screening for colorectal cancer. Lancet 1996, 348:1472-1477.

15. Kronborg O, Fenger C, Olsen J, Jørgensen OD, Søndergaard O: Randomised study of screening for colorectal cancer with faecal-occult-blood test. Lancet 1996, 348:1467-1471.

16. Lindholm $E$, Brevinge $H$, Haglind E: Survival benefit in a randomized clinical trial of faecal occult blood screening for colorectal cancer. $\mathrm{Br} J$ Surg 2008, 95:1029-1036.

17. Mandel JS, Church TR, Ederer F, Bond JH: Colorectal cancer mortality: effectiveness of biennial screening for fecal occult blood. J Natl Cancer Inst 1999, 91:434-437.

18. Zheng S, Chen K, Liu X, Ma X, Yu H, Chen K, Yao K, Zhou L, Wang L, Qiu P, Deng $Y$, Zhang $S$ : Cluster randomization trial of sequence mass screening for colorectal cancer. Dis Colon Rectum 2003, 46:51-58.

19. Saito H, Soma Y, Koeda J, Wada T, Kawaguchi H, Sobue T, Aisawa T, Yoshida Y: Reduction in risk of mortality from colorectal cancer by fecal occult blood screening with immunochemical hemagglutination test. A case-control study. Int J Cancer 1995, 61:465-469.

20. Saito H, Soma Y, Nakajima M, Koeda J, Kawaguchi H, Kakizaki R, Chiba R, Aisawa T, Munakata A: A case-control study evaluating occult blood screening for colorectal cancer with fecal occult blood test and an immunochemical hemagglutination test. Oncol Rep 2000, 7:815-819.

21. Thiis-Evensen E, Hoff GS, Sauer J, Langmark F, Majak BM, Vatn MH: Population-based surveillance by colonoscopy: effect on the incidence of colorectal cancer. Telemark Polyp Study I. Scand J Gastroenterol 1999, 34:414-420.

22. Muller $A D$, Sonnenberg $A$ : Protection by endoscopy against death from colorectal cancer. A case-control study among veterans. Arch Intern Med 1995, 155:1741-1748.

23. Newcomb PA, Norfleet RG, Storer BE, Surawicz TS, Marcus PM: Screening sigmoidoscopy and colorectal cancer mortality. N Engl J Med 1992, 326:653-657.

24. Winawer SJ, Zauber AG, Ho MN, O'Brien MJ, Gottlieb LS, Sternberg SS, Waye JD, Schapiro M, Bond JH, Panish JF, et al: Prevention of colorectal cancer by colonoscopic polypectomy. The National Polyp Study Workgroup. N Engl J Med 1993, 329:1977-1981.

25. Gondal G, Grotmol T, Hofstad B, Bretthauer M, Eide TJ, Hoff G: The Norwegian Colorectal Cancer Prevention (NORCAP) screening study: baseline findings and implementations for clinical work-up in age groups 50-64 years. Scand J Gastroenterol 2003, 38:635-642.

26. Atkin WS, Cook CF, Cuzick J, Edwards R, Northover JM, Wardle J, U. K. Flexible Sigmoidoscopy Screening Trial Investigators: Single flexible sigmoidoscopy screening to prevent colorectal cancer: baseline findings of a UK multicentre randomised trial. Lancet 2002, 359:1291-1300. 
27. Segnan N, Senore C, Andreoni B, Aste H, Bonelle L, Crosta C, Ferraris R, Gasperoni S, Penna A, Risio M, Rossini FP, Sciallero S, Zappa M, Atkin WS, SCORE Working Group-Italy: Baseline findings of the Italian multicenter randomized controlled trial of "once-only sigmoidoscopy"-SCORE. J Natl Cancer Inst 2002, 94:1763-1772.

28. Weissfeld JL, Schoen RE, Pinsky PF, Bresalier RS, Church T, Yurgalevitch S, Austin JH, Prorok PC, Gohagan JK, PLCO Project Team: Flexible sigmoidoscopy in the PLCO cancer screening trial: results from the baseline screening examination of a randomized trial. J Natl Cancer Inst 2005, 97:989-997.

29. Colorectal Cancer Facts \& Figures, American Cancer Society website. [http://www.cancer.org], accessed March 18, 2011.

30. Rim SH, Joseph DA, Steele CB, Thompson TD, Seeff LC: Colorectal Cancer Screening-United States 2002, 2004, 2006, and 2008. MMWR Surveill Summ 2011, 60(Suppl):42-46.

31. Meissner HI, Breen N, Klabunde CN, Vernon SW: Patterns of Colorectal Cancer Screening Uptake among Men and Women in the United States. Cancer Epidemiol Biomarkers Prev 2006, 15:389-394.

32. Klabunde CN, Lanier D, Nadel MR, McLeod C, Yuan G, Vernon SW: Colorectal cancer screening by primary care physicians: recommendations and practices, 2006-2007. Am J Prev Med 2009, 37:8-16.

33. Moawad FJ, Maydonovitch CL, Cullen PA, Barlow DS, Jenson DW, Cash BD: CT Colonography May Improve Colorectal Cancer Screening Compliance. Am J Roentgenol 2010, 195:1118-1123.

\section{Pre-publication history}

The pre-publication history for this paper can be accessed here: http://www.biomedcentral.com/1741-7015/9/133/prepub

doi:10.1186/1741-7015-9-133

Cite this article as: Warren et al: Septin 9 methylated DNA is a sensitive and specific blood test for colorectal cancer. BMC Medicine 2011 9:133.

\section{Submit your next manuscript to BioMed Central and take full advantage of:}

- Convenient online submission

- Thorough peer review

- No space constraints or color figure charges

- Immediate publication on acceptance

- Inclusion in PubMed, CAS, Scopus and Google Scholar

- Research which is freely available for redistribution

Submit your manuscript at www.biomedcentral.com/submit 